\title{
Ultrasonographic features of superficial and nodular basal cell carcinoma
}

\author{
Albina Nikolaevna Khlebnikova ${ }^{1}$, Vladimir Alekseevich Molochkov ${ }^{1}$, Elena Vladimirovna \\ Selezneva ${ }^{1}$, LyubovAnatolevna Belova ${ }^{1}$, Artur Petrovich Bezugly ${ }^{2}$, Anton Vladimirovich \\ Molochkov ${ }^{1}$
}

${ }^{1}$ M.F. Vladimirsky Moscow Regional Scientific Research Clinical Institute, Scientific-Practical Center of Dermatovenerology and Cosmetology, ${ }^{2}$ Laboratory of the Noninvasive Skin Diagnostics Clinic ANTA-Med, Moscow, Russia

\begin{abstract}
Aim: To describe the ultrasonographic findings of surface and nodular basal cell skin cancer (BCC) using high frequency ultrasonography. Materials and methods: We examined 60 primary BCCs in different locations with the High Frequency Ultrasound (HFU) system DUB Skin Scanner using $75 \mathrm{MHz}$ and $30 \mathrm{MHz}$ probes. Epidermis, dermis, and depth of tumors spread in the region of interest (ROI) were measured. Visually unchanged, contralateral skin areas were examined as the control. Results: The surface BCC most often had elongated contours, clear margins and hypoechoic structure, while the nodular $\mathrm{BCC}$ had round or oval outlines and diffusely hypo-heterogeneous structure with clear margins. Sclerodermiform BCCs were visualized as hypoechoic areas of irregular shape penetrating in the dermis, with wavy fuzzy margins. The average thickness of the surface BCC in the US examination was $556.28 \pm 136.95 \mu$, the nodular BCC thickness was $2439.71 \pm 865.92 \mu$ and the sclerodermiform thickness was $1500 \pm 325.33 \mu$. A statistically significant increase in the average thickness of tumors of the nodular and scleroderma forms was observed in comparison with the surface clinical variant $(\mathrm{p}<0.05)$. Hyperechoic inclusions were observed in $11 \%$ of the surface BCC's and in the $100 \%$ of the nodular BCC's. Their average number was $2 \pm 0.57$ and $4 \pm 4.8$, with the average area of $0.03 \pm 0.02 \mathrm{~mm}^{2}$ and $0.04 \pm 0.03 \mathrm{~mm}^{2}(\mathrm{p}>0.05)$, respectively. In the surface BCC, they were mainly located along the periphery of the hypoechoic zones. In nodular BCC, the inclusions had a peripheral and combined (center and peripheral) distribution. Conclusions: Ultrasound allows differentiating BCC as diffuse-heterogeneous, hypoechoic, formations in the dermis with distinct contours. Depending on the clinical picture, they differ in form, depth of bedding, as well as in the quantitative ratio and distribution of the point hyperechoic structures in them.
\end{abstract}

Keywords: basal cell carcinoma; high-frequency ultrasonography; hypoechoic zones; hyperechoic inclusions

\section{Introduction}

Basal cell carcinoma (BCC) is the most common malignant tumor of the skin. BCC is characterized by an extremely rare metastasis and the capacity for extensive growth, which leads to significant cosmetic and functional impairments $[1,2]$. There are several clinical forms

Received 02.08.2018 Accepted 07.11.2018

Med Ultrason

2018, Vol. 20, No 4, 475-479

Corresponding author: Bezugly Artur Petrovich

6-382 Pyatnitskoehgw, Moscow, 125464 Russia

Phone: +7916 2019009 ,

Fax: +7 4957544674

E-mail: DrArturBezugly@gmail.com of BCC: superficial, nodular, ulcerative, sclerodermiform and their combined variants [3]. The existing methods of BCC therapy should result in the complete elimination of tumor cells and the most acceptable cosmetic result [3]. The choice of treatment method depends on several criteria: the clinical form of the tumor, the earlier treatment methods, the histological pattern, localization and size of the tumor, the possibility of determining its margins and depth of invasion [4,5]. In the pre-therapy stage, these aims can be achieved through non-invasive diagnostic methods, ultrasound scanning in particular. Ultrasonography (US) is a non-invasive and safe method for examining tissue, based on ultrasonic waves reflecting from the interface of two media with different acoustic properties. The primary task of US is to study the struc- 
ture of a biological object, its location and dimensions, the characteristics of the distribution of tissue elements and its relationship with surrounding tissue and organs. In dermatological practice, probes with pulse generation frequency of 20 or 22, 30, 50, 75 and $100 \mathrm{MHz}$ are used [6-8]. High-frequency US (HFUS) provides high resolution allowing to differentiate the epidermis, dermis, subcutaneous fatty tissue and to visualize volume formations in various pathological processes, including BCC [8].

In earlier studies when using the ultrasound probe with a frequency of $20 \mathrm{MHz}, \mathrm{BCC}$ was detected as hypoechoic zones with local thickening of the epidermis and the dermis $[9,10]$. Taking into account the small size of the studied structures for the best visualization and determination of the level of invasion it is preferable to use the high-frequency probes (above $20 \mathrm{MHz}$ ). In addition, it is interesting to conduct the comparative study of the depth of invasion of BCC depending on its clinical variants.

Thus, the study aimed to explore ultrasonographic features of the superficial and nodular forms of BCC using 30 and $75 \mathrm{MHz}$ probes.

\section{Materials and methods}

We enrolled in our prospective study 47 patients with BCC admitted to the dermato-venereology and dermatooncology department of the Moscow Regional Research Clinical Institute between April 2017 and April 2018. The inclusion criteria were age over 18 years, clinical diagnosis of untreated primary superficial, nodular and sclerodermiform BCCs, localized on any part of the body, except the upper eyelids, ears, nose, scalp, up to $1 \mathrm{~cm}$ in diameter in the case of nodular BCCs. Patients with ulcerous BCCs, nodular BCCs with a diameter more than $1 \mathrm{~cm}$, BCCs of the upper eyelid, ears, nose, scalp, those in whom visualization of the BCCs on the highfrequency ultrasonography was difficult, were excluded. The study included 31 women and 16 men, aged 56 to 73 years (average of $64.8 \pm 5.3$ years). The number of BCCs ranged from 1 to 6 per patient. The local research ethics committee approved the study. All patients were informed of the study protocol and the requirements for the study participation and written informed consent was obtained before the procedure.

All tumors were clinically divided into 3 groups: superficial, nodular and sclerodermiform. The superficial $\mathrm{BCC}$ was represented as a pink-colored plaque with a diameter of 1 to $5 \mathrm{~cm}$ on the surface of which the exfoliation, small skin crusts, areas of hypo-or hyperpigmentation and atrophy were noted. The nodular BCC was characterized by node or nodule of hemispherical shape with a size of 0.5 to $1 \mathrm{~cm}$ of a pale pink color with a smooth surface and telangiectasia. The sclerodermiform BCC represents the infiltrative solid plaque with a size of 0.5 to $1.5 \mathrm{~cm}$ with clear waxy-colored borders with telangiectasia on the surface. The clinical diagnosis of BCCs was confirmed by histology. Biopsy techniques for BCCs included punch biopsy and excisional biopsy.

The informativity of the HFUS study in the area of scalp was reduced because of the large number of hair follicles that impede the visualization of the tumor, in the area of the ulcerated BCCs because of inflammable infiltrate which does not allow to identify the posterior border of the tumor and in the upper eyelids, ears and nose - due to the shape and size of the ultrasound probes which do not allow to conduct examination on prominent areas of the body.

Totally 60 BCCs were scanned using the 30 and 75 $\mathrm{MHz}$ probes, with axial resolution of 52 and $21 \mu$ and depth of scanning of 8 and $4 \mathrm{~mm}$, with axial resolution of 52 and $21 \mu$ and depth of scanning of 8 and $4 \mathrm{~mm}$, respectively. US-scanning was performed by a dermatologist with 8 years of experience in the HFUS technique. Epidermis, dermis and tumor thickness in the region of interest (ROI) were measured. The epidermis was defined as a band of increased echogenicity, well delineated from the underlying dermis, with a distinct internal contour. The dermis had the clear demarcation from the subcutaneous fat and uniform thickness. The tumors were defined as hypoechoic zones located in the different parts of the dermis. Contralateral healthy areas upon visual inspection were scanned as the control. For visualization and calculation of the quantitative indicators, the software jointly developed by the company tpm GmbH (Germany) and the company ANTA-Med (Russia) was applied.

\section{Statistical analysis}

The study results were statistically processed by the licensed Statistica 7 software. The data obtained were analyzed using parametric statistical methods. The average value and the standard deviation in the compared groups were calculated. To determine the statistical significance of the differences in the mean values, the Student's t-test was used. Statistical significance was set at a p level of less than 0.05 .

\section{Results}

The superficial BCC was found in $35(58 \%)$ cases, nodular in $22(37 \%)$ cases and sclerodermiform in $3(5 \%)$ cases.

At ultrasound scanning, all superficial BCCs appeared as hypoechoic zones located directly beneath the epidermis, most often of the elongated shape with distinct contours (fig 1). 


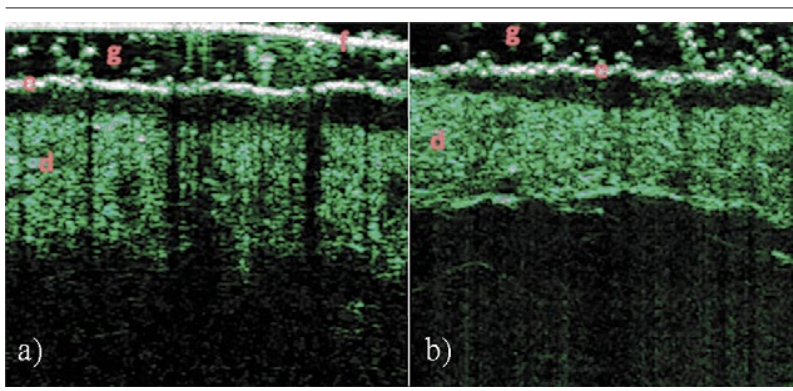

Fig 1. Scans of the superficial BCC ( $\mathrm{a}$ and b). The hypoechoic zones are defined as the formations of an oblong form with distinct lateral and lower margins. $75 \mathrm{MHz}$ probe. $\mathrm{f}-$ foil on the tip of the probe, $\mathrm{g}-\mathrm{gel}$, e - epidermis, $\mathrm{d}-$ dermis.

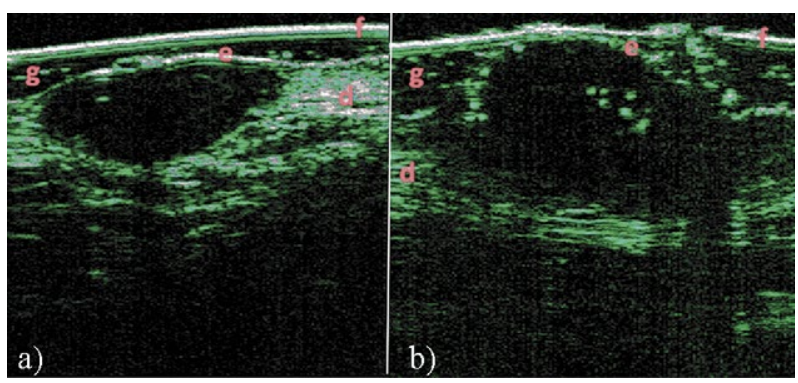

Fig 2. Scans of the nodular BCC ( $a$ and b). The hypoechoic zones are defined as the formations of the rounded shape, with hyperechoic inclusions in the structure. $30 \mathrm{MHz}$ probe. $\mathrm{f}-$ foil on the tip of the probe, $\mathrm{g}-\mathrm{gel}, \mathrm{e}$ - epidermis, $\mathrm{d}$ - dermis.

All nodular BCCs featured hypoechoic zones of rounded or oval outlines that rose above the unaltered skin surface and had the diffusely heterogeneous hypoechoic structure with distinct lateral and lower margins (fig 2).

All sclerodermiform BCCs featured hypoechoic regions of an irregular shape, infiltrating dermis and indistinct lateral and lower margins (fig 3 ).

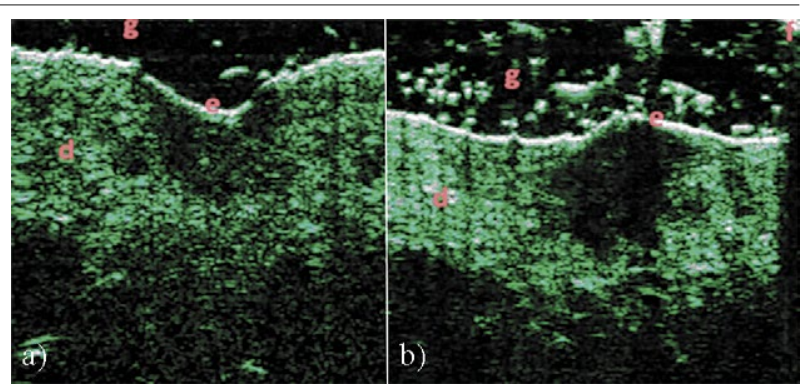

Fig 3. Scans of the sclerodermiform BCC ( $\mathrm{a}$ and $\mathrm{b}$ ). The hypoechoic zones are defined as the formations of the irregular shape, infiltrating dermis, with unclear lateral and lower margins. $75 \mathrm{MHz}$ probe. $\mathrm{f}-$ foil on the tip of the probe, $\mathrm{g}-$ gel, e-epidermis, $d$ - dermis.

The average values of the thickness of the epidermis, dermis and hypoechoic zones in various clinical variants of $\mathrm{BCC}$ and the control are presented in table I. There was a statistically significant increase in the average thickness of hypoechoic zones - in the nodular and sclerodermiform BCCs when compared to the superficial BCCs $(p<0.05)$. The difference between the epidermis thickness in the sclerodermiform BCCs and the contralateral regions was also statistically significant $(p<0.05)$.

Hyperechoic inclusions displaying a punctiform pattern were recorded in the structure of superficial and nodular BCCs in $4(11 \%)$ and $22(100 \%)$ cases, respectively. Scans of all superficial tumors showed hyperechoic structures along the periphery of hypoechoic zones. Their number varied from 1 to 3 and averaged $2 \pm 0.5$. US examination of nodular BCCs revealed peripheral distribution of inclusions in $12(55 \%)$ cases, combined (center and peripheral) distribution in $8(36 \%)$ cases and central distribution in $2(9 \%)$ cases. Among the instances with combined localization, hyperechoic structures were located predominantly in the center of tumors in $5(63 \%)$

Table I. Comparative characteristics of the epidermis, dermis and hypoechoic zones thickness in the lesion of various clinical forms of $\mathrm{BCC}$ and in the control

\begin{tabular}{|c|c|c|c|c|c|}
\hline $\begin{array}{l}\mathrm{BCC} \\
\text { clinical form }\end{array}$ & $\begin{array}{l}\text { Epidermis } \\
\text { thickness in BCC } \\
\text { lesions }(\mathrm{mm})\end{array}$ & $\begin{array}{l}\text { Epidermis } \\
\text { thickness in } \\
\text { control }(\mathbf{m m})\end{array}$ & $\begin{array}{l}\text { Dermis } \\
\text { thickness in BCC } \\
\text { lesions }(\mathrm{mm})\end{array}$ & $\begin{array}{l}\text { Dermis } \\
\text { thickness } \\
\text { in control }(\mathrm{mm})\end{array}$ & $\begin{array}{l}\text { Thickness of } \\
\text { hypoechoic zones } \\
\text { in BCC lesions }(\mathrm{mm})\end{array}$ \\
\hline Superficial & $\begin{array}{l}0.090 \pm 0.019 \\
\mathrm{p}=0.552\end{array}$ & $0.075 \pm 0.016$ & $\begin{array}{l}1.358 \pm 0.299 \\
\mathrm{p}=0.761\end{array}$ & $1.237 \pm 0.368$ & $0.556 \pm 0.137$ \\
\hline Nodular & $\begin{array}{l}0.097 \pm 0.024 \\
p=0.933\end{array}$ & $0.100 \pm 0.016$ & $\begin{array}{l}3.155 \pm 0.975 \\
p=0.266\end{array}$ & $1.861 \pm 0.604$ & $2.440 \pm 0.866$ \\
\hline Sclerodermiform & $\begin{array}{l}0.070 \pm 0.002 \\
\mathbf{p}=\mathbf{0 . 0 1 9} *\end{array}$ & $0.049 \pm 0.003$ & $\begin{array}{l}1.678 \pm 0.284 \\
p=0.676\end{array}$ & $1.544 \pm 0.060$ & $1.500 \pm 0.325$ \\
\hline \multicolumn{5}{|c|}{$\begin{array}{l}\text { Difference between the thickness of the hypoechoic zones in superficial and nodular BCCs } \\
\text { Difference between the thickness of the hypoechoic zones in superficial and sclerodermiform BCCs } \\
\text { Difference between the thickness of the hypoechoic zones in nodular and sclerodermiform BCCs }\end{array}$} & $\begin{array}{l}\mathbf{p}=\mathbf{0 . 0 3 6} * \\
\mathbf{p}=\mathbf{0 . 0 1 1} * \\
\mathrm{p}=0.320\end{array}$ \\
\hline
\end{tabular}

The results are expressed as mean \pm standard deviation; * differences in the groups are statistically significant, $\mathrm{p}<0.05$ 
cases and on the periphery of the lesions in $3(37 \%)$ cases. The number of hyperechoic inclusions ranged from 1 to 26 per lesion and averaged $7.4 \pm 4.8$. Their average area within the nodular and superficial BCCs was $0.04 \pm 0.03$ $\mathrm{mm}^{2}$ and $0.03 \pm 0.02 \mathrm{~mm}^{2}$, respectively, and their comparative analysis revealed no statistically significant difference $(\mathrm{p}>0.05)$.

Ultrasound examination showed that the average thickness of the superficial BCCs was $0.556 \pm 0.137 \mathrm{~mm}$, the nodular BCCs thickness was $2.440 \pm 0.866 \mathrm{~mm}$ and the sclerodermiform BCCs thickness was $1.500 \pm 0.325$ $\mathrm{mm}$. A statistically significant increase in the average thickness of the nodular and sclerodermiform BCCs was observed when compared with the superficial clinical variants $(\mathrm{p}<0.05)$.

\section{Discussions}

All clinical variants of the BCCs were defined as hypoechoic zones located directly beneath the epidermis and propagating into the dermis at varying depths. These data are consistent with the results of other authors who described BCCs as voluminous, hypoechoic areas, round or oval, with diffusely heterogeneous structure. Local thickening of the epidermis and dermis was noted in the area of tumors [9]. Differentiation of skin layers was preserved; the upper contour and lateral borders of the tumors were clearly visualized [10]. A similar US picture of BCCs was described by Desai et al and SchmidWendtner et al who used the $20 \mathrm{MHz}$ frequency probe and defined BCCs as alternating hypo- and hyperechoic areas, with no clear margins between the tumor and the perifocal infiltrate $[11,12]$. Other authors reported using the $22 \mathrm{MHz}$ transducer and described BCC lesions as heterogeneous, hypoechoic formations in the dermis with a regular contour and large, hyperechoic internal signals [13]. In our study, we used the $75 \mathrm{MHz}$ frequency probes for superficial and sclerodermiform BCCs and $30 \mathrm{MHz}$ frequency probe for the nodular BCCs, that contributed to the more accurate visualization of the margins, sizes and structure of tumors.

The superficial BCCs most often had elongated contours and clear margins; while the nodular BCCs had round or oval outlines and diffusely-heterogeneous structure [14-18]. Scans of sclerodermiform BCCs featured hypoechoic areas, infiltrating dermis, with unclear margins. The depth of invasion of BCC depends on the morphological structure. Earlier when comparing the histological types of BCCs and the depth of distribution of hypoechoic zones during the US scanning it was shown that the average thickness of the hypoechoic zones during the scanning of micronodular types of tumors was
$2.01 \mathrm{~mm}$, infiltrative $-1.82 \mathrm{~mm}$, nodular $-1.68 \mathrm{~mm}$ and superficial $-0.71 \mathrm{~mm}$ [19]. In our study, for the first time, the depth of invasion of the BCC during the US scanning with the clinical variants of the lesion was determined and compared between BCCs forms.

HFUS imaging allows the visualization of shape and margins of the tumors, assessing the size and depth of its invasion, and, in some cases, determining its structural features. In our study, hyperechoic inclusions displaying a punctiform pattern were recorded in the structure of $11 \%$ of superficial BCCs and in $100 \%$ of nodular BCCs. Our results agree with those reported by other researchers. For example, Bobadilla et al and Marmur et al identified multiple hyperechoic structures of various shapes and sizes, which were revealed by histological analysis to be calcifications, corneous cysts and necrosis areas of tumor cells $[9,20]$. Some authors used the presence of similar structures in the tumor as a differential diagnostic feature, which makes it possible to distinguish between BCC and skin melanoma [21]. Our results, for the first time, show that the presence of more than three hyperechoic inclusions in the hypoechoic lesions is the additional US characteristic of the clinically nodular BCC.

Our study has some limits. The HFUS skin imaging has high resolution and according to the ultrasound physics, the depth of penetration is limited. For $30 \mathrm{MHz}$ the maximal examination depths $6-8 \mathrm{~mm}$ and for $75 \mathrm{MHz}$ 3-4 mm. Also, objects with a diameter higher than 13-15 $\mathrm{mm}$ could not be properly scanned due to the limited scan width. The lack of intra- and interobserver agreement is the main limit of the study.

\section{Conclusion}

The US pattern of the BCC lesions was characterized by the presence of hypo-heteroechoic areas in the dermis. They had sharp contours within the superficial and nodular BCCs and no clear margins within the sclerodermiform BCCs. Superficial BCCs presented as hypoechoic areas, nodular BCCs - as hypoechoic zones with hyperechoic inclusions displaying a punctuation pattern and sclerodermiform BCCs appeared as hypoechoic areas infiltrating dermis.

\section{References}

1. Nakayama M, Tabuchi K, Nakamura Y, Hara A. Basal cell carcinoma of the head and neck. J Skin Cancer 2011; 2011:496910.

2. Baheti AD., Tirumani SH, Giardino A, et al. Basal cell carcinoma: a comprehensive review for the radiologist. AJR Am J Roentgenol 2015;204:W132-W140. 
3. Marzuka AG, Book SE. Basal Cell Carcinoma: Pathogenesis, Epidemiology, Clinical Features, Diagnosis, Histopathology, and Management. Yale J Biol Med 2015;88:167179.

4. Telfer NR, Colver GB, Morton CA; British Association of Dermatologists. Guidelines for the management of basal cell carcinoma. Br J Dermatol 2008; 159:35-48.

5. Trakatelli M, Morton C, Nagore E, et al. Update of the European guidelines for basal cell carcinoma management. Eur J Dermatol 2014;24:312-329.

6. Bhatt KD, Tambe SA, Jerajani HR, Dhurat RS. Utility of high-frequency ultrasonography in the diagnosis of benign and malignant skin tumors. Indian J Dermatol Venereol Leprol 2017;83:162-182.

7. Jasaitiene D, Valiukeviciene S, Linkeviciute G, Raisutis R, Jasiuniene E, Kazys R. Principles of high-frequency ultrasonography for investigation of skin pathology. J Eur Acad Dermatol Venerol 2011;25:375-382.

8. Bezugly A. High frequency ultrasound study of skin tumors in dermatological and aesthetic practice. Med Ultrason 2015;17:541-544.

9. Bobadilla F, Wortsman X, Munoz C, Segovia L, Espinoza M. Jemec GB. Pre-surgical high-resolution ultrasound of facial basal cell carcinoma: correlation with histology. Cancer Imaging 2008;8:163-172.

10. Hinz T, Ehler LK, Hornung T, et al. Preoperative characterization of basal cell carcinoma comparing tumour thickness measurement by optical coherence tomography, 20$\mathrm{mhz}$ ultrasound and histopathology. Acta DermVenereol 2012;92:132-137.

11. Desai TD, Desai AD, Horowitz DC, Kartono F, Wahl T. The use of high-frequency ultrasound in the evaluation of superficial and nodular basal cell carcinomas. Dermatol Surg 2007;33:1220-1227.
12. Schmid-Wendtner M, Burgdorf W. Ultrasound scanning in dermatology. Arch Dermatol 2005;141:217-224.

13. Barcaui Ede O, Carvalho AC, Valiante PM, Barcaui CB. High-frequency ultrasound associated with dermoscopy in pre-operative evaluation of basal cell carcinoma. An Bras Dermatol 2014;89:828-831.

14. Kučinskiene V, Samulèniene D, Gineikiene A, Raišutis R, Kažys R, Valiukevičiene S. Preoperative assessment of skin tumor thickness and structure using 14-MHz ultrasound. Medicina (Kaunas) 2014;50:150-155.

15. Vilana R, Puig S, Sanchez M, et al. Preoperative assessment of cutaneous melanoma thickness using 10-MHz sonography. AJR Am J Roentgenol 2009;193:639-643.

16. Music MM, Hertl K, Kadivec M, Pavlović MD, Hocevar M. Pre-operative ultrasound with a $12-15 \mathrm{MHz}$ linear probe reliably differentiates between melanoma thicker and thinner than $1 \mathrm{~mm}$. J Eur Acad Dermatol Venereol 2010;24:1105-1108.

17. Ballester-Sánchez R, Pons-Llanas O, Llavador-Ros M, et al. Depth determination of skin cancers treated with superficial brachytherapy: ultrasound vs. histopathology. J Contemp Brachytherapy 2015;6:356-361.

18. Rippon MG, Springett K, Walmsley R, Patrick K, Millson S. Ultrasound assessment of skin and wound tissue: comparison with histology. Skin Res Technol 1998;4:147-154.

19. Welsch MJ, Troian BM, Hale L, DelTondo J, Helm KF, Clarke LE. Basal cell carcinoma characteristics as predictors of depth of invasion. J Am Acad Dermatol 2012;67:47-53.

20. Marmur ES, Berkowitz EZ, Fuchs BS, Singer GK, Yoo JY. Use of high frequency, high -resolution ultrasound before Mohs surgery. Dermatol Surg 2010;36:841-847.

21. Uhara H, Hayashi K, Koga H, Saida T. Multiple hypersonographic spots in basal cell carcinoma. Dermatol Surg 2007;33:1215-1219. 